\title{
Hepatic energy state is regulated by glucagon receptor signaling in mice
}

\author{
Eric D. Berglund, ${ }^{1}$ Robert S. Lee-Young, ${ }^{1}$ Daniel G. Lustig,, Sara E. Lynes, ${ }^{1}$ E. Patrick Donahue, ${ }^{1}$ \\ Raul C. Camacho, ${ }^{1}$ M. Elizabeth Meredith, ${ }^{1}$ Mark A. Magnuson, ${ }^{1}$ \\ Maureen J. Charron, ${ }^{2}$ and David H. Wasserman 1,3
}

\begin{abstract}
'Department of Molecular Physiology and Biophysics, Vanderbilt University School of Medicine, Nashville, Tennessee, USA. ${ }^{2}$ Department of Biochemistry, Albert Einstein School of Medicine, New York, New York, USA. ${ }^{3}$ Vanderbilt-NIH Mouse Metabolic Phenotyping Center, Vanderbilt University School of Medicine, Nashville, Tennessee, USA.
\end{abstract}

\begin{abstract}
The hepatic energy state, defined by adenine nucleotide levels, couples metabolic pathways with energy requirements. This coupling is fundamental in the adaptive response to many conditions and is impaired in metabolic disease. We have found that the hepatic energy state is substantially reduced following exercise, fasting, and exposure to other metabolic stressors in C57BL/6 mice. Glucagon receptor signaling was hypothesized to mediate this reduction because increased plasma levels of glucagon are characteristic of metabolic stress and because this hormone stimulates energy consumption linked to increased gluconeogenic flux through cytosolic phosphoenolpyruvate carboxykinase (PEPCK-C) and associated pathways. We developed what we believe to be a novel hyperglucagonemic-euglycemic clamp to isolate an increment in glucagon levels while maintaining fasting glucose and insulin. Metabolic stress and a physiological rise in glucagon lowered the hepatic energy state and amplified AMP-activated protein kinase signaling in control mice, but these changes were abolished in glucagon receptor-null mice and mice with liver-specific PEPCK-C deletion. 129X1/Sv mice, which do not mount a glucagon response to hypoglycemia, displayed an increased hepatic energy state compared with $\mathrm{C} 57 \mathrm{BL} / 6$ mice in which glucagon was elevated. Taken together, these data demonstrate in vivo that the hepatic energy state is sensitive to glucagon receptor activation and requires PEPCK-C, thus providing new insights into liver metabolism.
\end{abstract}

\section{Introduction}

The energy state in the cell is defined by adenine nucleotide levels and is critically coupled to nearly all metabolic processes (1). In the cell, the adenine nucleotides ATP, ADP, and AMP are tied directly or indirectly to all energetic pathways and allosterically control numerous regulatory enzymes (2-6). Changes in adenine nucleotides typically occur such that ATP and AMP deviate in reciprocal directions, while ADP remains constant (1). Such changes are the basis for using the ratio $\operatorname{AMP} / \operatorname{ATP}(1,7)$ or the equation for cellular energy charge $([\mathrm{ATP}+(0.5 \times \mathrm{ADP})] /[\mathrm{ATP}+\mathrm{ADP}+\mathrm{AMP}])$ $(8,9)$ as indices of the metabolic environment. Metabolic stress is thus characterized by a rise in AMP paired with a fall in ATP levels, reflecting a decrease in energy state. A fall in energy state is of considerable importance, in part due to the regulatory role of AMP/ATP ratios on AMPK activity (10). AMPK is a metabolic switch sensitive to high AMP/ATP ratios and functions to protect the energy state by inhibiting ATP-consuming processes while stimulating ATP-producing processes. (10).

In most tissues, the environment is controlled to maintain a high energy state (low AMP/ATP ratio). In skeletal muscle, for example, creatine kinase limits reductions in ATP during conditions such as exercise, when energy utilization is accelerated $(11,12)$. The liver, in contrast, lacks creatine kinase, and exercise has been shown to markedly decrease the hepatic energy state and increase the phosphorylation of AMPK $(11,13)$. The regulatory significance of

Conflict of interest: The authors have declared that no conflict of interest exists.

Nonstandard abbreviations used: ACC, acetyl-CoA carboxylase; GIR, glucose infusion rate; PEPCK-C, cytosolic phosphoenolpyruvate carboxykinase; STZ, streptozotocin; TAN, total adenine nucleotide.

Citation for this article: J. Clin. Invest. 119:2412-2422 (2009). doi:10.1172/JCI38650. deviations in the hepatic energy state is further illustrated by studies using 5-aminoimidazole-4-carboxamide-1- $\beta$-O-ribofuranoside (AICAR). AICAR is converted to the AMP analog AICA-riboside (ZMP) upon entering the cell and thus mimics an increase in cellular stress. In previous studies, AICAR has been shown to increase energy-producing pathways in the liver relative to energy-consuming pathways (14-16). The regulatory potential of the hepatic energy state is powerful, considering the key role of the liver in whole-body carbohydrate, lipid, and protein metabolism.

While the regulatory potential of an energy-depleted state in the liver is clear, the conditions that result in energy depletion and the mechanisms by which this state occurs are not well understood. Our goals, therefore, were to test the hypotheses that (a) reductions in the hepatic energy state are a physiological phenomenon not isolated to exhaustive exercise and (b) glucagon receptor activation mediates a lowered hepatic energy state sufficient to activate AMPK through a process requiring cytosolic phosphoenolpyruvate carboxykinase (PEPCK-C). The foundation for this latter hypothesis is that a rise in plasma glucagon is characteristic of metabolic stress (17-24) and increased hormone levels are shown to amplify phosphorylation of AMPK in vitro and in perfused liver $(25,26)$. Studies in vivo have also shown that hepatic glucagon action is the primary determinant of gluconeogenesis via PEPCK-C and stimulation of coupled pathways, including fatty acid activation and ureagenesis, which are required to offset higher glucose use in the body during exercise (27-29).

These hypotheses were tested in conscious mice in response to metabolic stress associated with elevated glucagon; metabolic stress in mice with genetic deletion of the glucagon receptor; hypoglycemia in $129 \times 1 / \mathrm{Sv}$ mice, in whom the glucagon response to a fall in glucose is blunted; metabolic stress in which glucagon-stim- 

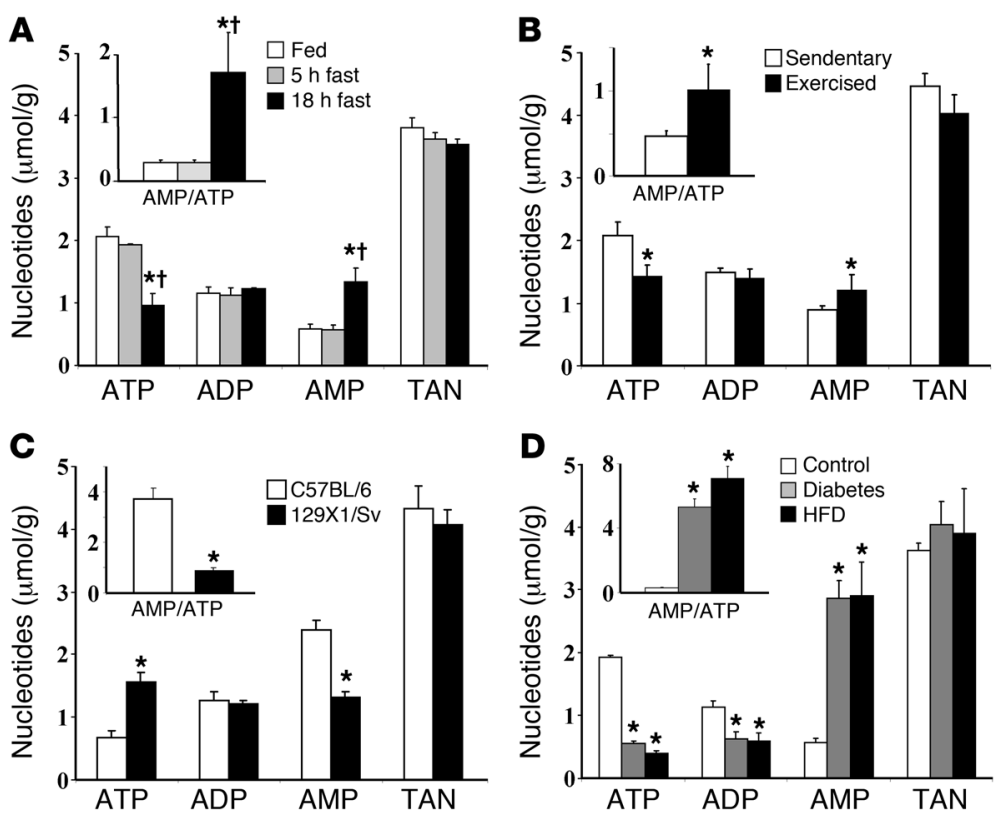

\section{Figure 1}

Metabolic stress reduces hepatic energy state in C57BL/6 mice. Hepatic adenine nucleotides measured by HPLC in mice following (A) a 5- or 18-hour fast ( $n=6$-8/group), (B) maximal treadmill exercise (starting at $10 \mathrm{~m} / \mathrm{min}$, adding $4 \mathrm{~m} / \mathrm{min}$ every 3 minutes, after a 5 -hour fast; $n=6-8 /$ group), (C) insulin-induced hypoglycemic clamp ( $n=6-8 /$ group), and (D) with STZ-induced diabetes (1 s.c. injection of $150 \mathrm{mg} / \mathrm{kg} ; n=6 /$ group) or fed a high-fat diet (HFD; $60 \%$ fat by kcal for 9 weeks) and after fasting for 5 hours ( $n=4 /$ group). Hepatic AMP/ATP ratios are also shown for each condition. TAN content is the sum total of ATP, ADP, and AMP. All mice were 12 weeks of age and on a C57BL/6 background except in the experiments shown in $\mathbf{C}$, in which $129 \times 1 / \mathrm{Sv}$ mice were also studied. Mice were compared with respective controls (fed, C57BL/6, and 5-hour-fasted chow-fed mice). Data are presented as mean \pm SEM. ${ }^{*} P<0.05$ compared with controls. ${ }^{\dagger} P<0.05$ compared with 5-hour-fasted mice. ulated flux through PEPCK-C is inhibited by liver-specific deletion of the enzyme; and a physiological increment in glucagon levels. Experiments in the last situation were carried out by developing a hyperglucagonemic-euglycemic clamp technique which, for what we believe is the first time, makes it possible for an increment in glucagon levels to be examined while maintaining euglycemia and fasting insulin. Collectively, our studies show that reductions in hepatic energy state due to metabolic stress are provoked by glucagon receptor activation and PEPCK-C.

\section{Results}

\section{Metabolic stress induces dramatic changes in bepatic adenine nucleotide levels}

Liver adenine nucleotides were assessed in C57BL/6 mice following metabolic stressors in which glucagon has been shown to be elevated (fasting, exercise, hypoglycemia, diabetes, and high-fat diet; refs. 17-24). In response to an 18-hour fast, hepatic ATP, ADP, and AMP levels were decreased, unchanged, and increased, respectively, resulting in a nearly 6-fold increase in AMP/ATP ratios compared with fed mice and mice fasted for 5 hours (Figure 1A). Changes in adenine nucleotides induced by an 18 -hour fast corresponded to a fall in hepatic energy charge from $0.69 \pm 0.02$ and $0.69 \pm 0.03$ in fed and 5-hour-fasted mice, respectively, to $0.46 \pm 0.05(P<0.05)$. In response to maximal treadmill exercise, hepatic ATP, ADP, and AMP levels were also decreased, unchanged, and increased, respectively, compared with sedentary mice (Figure 1B). Exercise lowered hepatic energy charge from $0.69 \pm 0.03$ in sedentary mice to $0.33 \pm 0.02$ $(P<0.05)$, consistent with previous findings $(11)$.

Insulin-induced hypoglycemia also led to marked changes in hepatic AMP and ATP concentrations, while ADP did not change in C57BL/6 mice (Figure 1C). Hypoglycemia-induced changes in adenine nucleotide corresponded to a significant increase in AMP/ATP ratios (Figure 1C). In 129X1/Sv mice, a strain previously shown to lack a glucagon response to insulin-induced hypoglycemia (30), hepatic adenine nucleotides remained relatively unchanged (Figure 1C) despite hypoglycemia, such that the energy charge was $0.53 \pm 0.02$. This was in contrast to C $57 \mathrm{BL} / 6$ mice, in which glucagon levels were increased and hepatic energy charge was diminished to $0.30 \pm 0.02(P<0.05$ vs. $129 \mathrm{X} 1 / \mathrm{Sv})$. Hepatic adenine nucleotides were similar in C57BL/6 and $129 \mathrm{X} 1 / \mathrm{Sv}$ mice fasted for 5 hours, corresponding to basal energy charges of $0.71 \pm 0.03$ and $0.70 \pm 0.04$, respectively.

In addition to these acute physiological stresses, streptozotocininduced (STZ-induced) diabetes and a high-fat diet led to decreased ATP and ADP as well as increased AMP levels in the liver (Figure 1D), corresponding to approximately 17 - and 23-fold increases, respectively, in hepatic AMP/ATP ratios compared with control mice (Figure 1D). The hepatic energy charge was reduced from $0.70 \pm 0.02$ in healthy control mice to $0.22 \pm 0.01$ and $0.18 \pm 0.01$ in STZ-induced diabetes and high-fat fed mice, respectively $(P<0.05$ in both conditions). Total adenine nucleotide (TAN) content in the liver (Figure 1) and energy state in the gastrocnemius (Supplemental Table 1; supplemental material available online with this article; doi:10.1172/JCI38650DS1) were unchanged under all conditions, consistent with previous results (11).

\section{Glucagon action mediates changes in the hepatic energy state associated with metabolic stress}

Given that the aforementioned stressors are associated with elevated glucagon levels, we performed fasting and exercise protocols in mice lacking the glucagon receptor $\left(\mathrm{Gcgr}^{-}\right)$and wild-type littermate mice $\left(\mathrm{Gcgr}^{+/+}\right)$to test the requirement for glucagon receptor activation in mediating the effects of metabolic stress on hepatic adenine nucleotides. Body weight was similar between genotypes $\left(24.0 \pm 1.0\right.$ vs. $23.5 \pm 0.8 \mathrm{~g}$ for $\mathrm{Gcgr}^{+/+}$and $\mathrm{Gcgr}^{-/-}$mice, respectively). In $\mathrm{Gcgr}^{+/+}$mice, fasting and exercise (Figure 2, A and B) altered ATP, $\mathrm{ADP}$, and AMP levels similar to the results obtained in C57BL/6 mice (see Figure 1, A and B). Fasting- and exercise-induced changes in $\mathrm{Gcgr}^{+/+}$liver adenine nucleotides corresponded to a fall in hepatic energy charge from $0.69 \pm 0.03$ and $0.75 \pm 0.08$ in fed and sedentary control mice, respectively, to $0.47 \pm 0.03$ and $0.45 \pm 0.05$, 

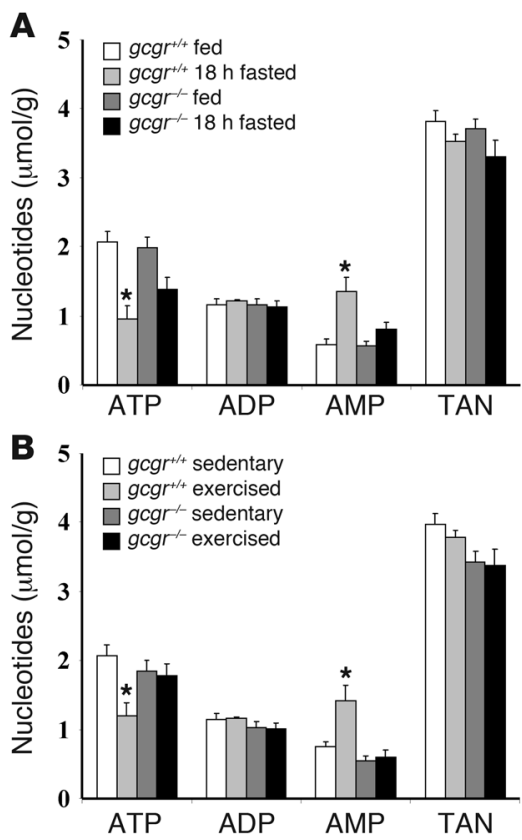

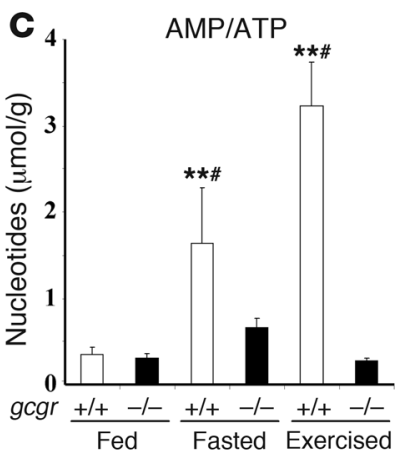

Figure 2

Glucagon receptor is required for metabolic stress-induced reductions in hepatic energy state. Hepatic adenine nucleotides measured by HPLC in $\mathrm{Gcgr}^{+/+}$and $\mathrm{Gcgr}^{-/}$littermate mice ( $n=8 /$ group) following (A) an 18-hour overnight fast and (B) maximal treadmill exercise (starting at $10 \mathrm{~m} / \mathrm{min}$ and adding $4 \mathrm{~m} / \mathrm{min}$ every 3 minutes, after a 5 -hour fast). Mice were compared with fed controls or with mice that remained sedentary on the treadmill for 30 minutes. (C) Hepatic AMP/ATP ratios for each condition shown in $\mathbf{A}$ and $\mathbf{B}$. There were no differences between fed and 5-hour-fasted control mice. Data are presented as mean \pm SEM. ${ }^{*} P<0.05$ compared with all other groups. ${ }^{* *} P<0.05$ compared with $\mathrm{Gcgr}^{+/+}$control mice. $\# P<0.05$ compared with $\mathrm{Gcgr}^{-1}$. respectively ( $P<0.05$ in both conditions). In $\mathrm{Gcgr}^{-/}$mice, however, fasting-induced changes in hepatic adenine nucleotides were attenuated (Figure 2A) and exercise-induced changes were absent (Figure $2 \mathrm{~B}$ ). In both conditions, changes in hepatic AMP/ATP ratios (Figure 2C) or energy charge were absent in $\mathrm{Gcgr} /$ - mice compared with $\mathrm{Gcgr}^{+/+}$mice. The absence of exercise-induced changes in the hepatic energy state of $\mathrm{Gcgr}^{-/}$mice did not alter exercise capacity $(22.6 \pm 2.1$ vs. $24.9 \pm 1.9 \mathrm{~min})$. TAN in the liver did not change in any group (Figure 2, A and B). The gastrocnemius energy state did not change in either genotype, despite fasting or exhaustive work (data not shown).

\section{PEPCK-C expression is essential for fasting-induced changes in the bepatic energy state}

The requirement for gluconeogenic flux through PEPCK-C in provoking changes in the hepatic energy state was initially tested using an 18-hour fast as a stressor in Pck lox/lox and Pcklox/lox Alb-cre mice. As shown in Figure 3, hepatic levels of ATP, ADP, and AMP were decreased, unchanged, and increased, respectively, by an 18-hour fast in $P c k^{l o x} /$ lox mice, corresponding to a 3-fold increase in hepatic AMP/ATP ratios compared with fed controls (Figure 3). Fasting lowered the energy charge from $0.70 \pm 0.04$ in fed mice to $0.44 \pm 0.07$ in $P c k^{l o x} / l o x$ mice $(P<0.05)$. In $P c k^{l o x} /$ lox Alb-cre littermates, fasting-induced changes in hepatic adenine nucleotides were absent (Figure 3).

\section{Studies using the byperglucagonemic-englycemic clamp}

A physiological increment in glucagon levels under euglycemic conditions lowers the hepatic energy state. An in vivo clamp was developed to isolate hepatic glucagon action. Phloridzin and exogenous glucose were infused to create a euglycemic background. Glucagon was then infused, and the glucose infusion rate (GIR) was adjusted to maintain euglycemia. As shown in Figure 4A, plasma glucagon was significantly increased in $\mathrm{Gcgr}^{+/+}$mice. Glucagon levels in glucagon- and vehicle-infused $\mathrm{Gcgr}^{-1}$ mice were greater than $8,000 \mathrm{ng} / \mathrm{l}$, consistent with previous data (31). Clamp insulin lev- els were unchanged (Figure 4B), and the target euglycemia levels of approximately $8.5 \mathrm{mmol} / \mathrm{l}$ were achieved in all groups (Figure 4C). Insulin was also assessed during the non-steady-state period at 30 minutes in separate experiments and was not different from basal (insulin was $186 \pm 18,197 \pm 21,155 \pm 11$, and $151 \pm 15 \mathrm{pmol} / \mathrm{l}$ at 0 minutes and $198 \pm 31,161 \pm 23,137 \pm 17$, and $160 \pm 18 \mathrm{pmol} / \mathrm{l}$ at 30 minutes in $\mathrm{Gcgr}^{+/+}$plus saline, $\mathrm{Gcgr}^{+/+}$plus glucagon, $\mathrm{Gcgr}^{/-}$plus vehicle, and $\mathrm{Gcgr}^{--}$plus glucagon mice) The GIR needed to maintain blood glucose at about $8.5 \mathrm{mmol} / \mathrm{l}$ is shown in Figure 4D.

The increment in glucagon levels during the clamp resulted in adenine nucleotide levels comparable to metabolic stressors in $\mathrm{Gcgr}^{+/+}$and $\mathrm{Gcgr}^{-/-}$mice. In Gcgr ${ }^{+/+}$mice, elevated glucagon was associated with decreased ATP, unchanged ADP, and increased AMP levels compared to all other groups (Figure 5A), such that hepatic AMP/ATP ratios were markedly increased (Figure 5A). Energy charge was significantly lowered, from $0.67 \pm 0.01$ in vehicle-infused $\mathrm{Gcgr}^{+/+}$to $0.46 \pm 0.09$ in glucagon-infused $\mathrm{Gcgr}^{+/+}$mice

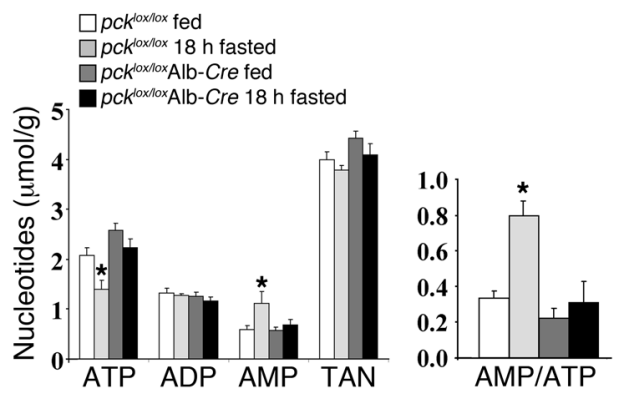

Figure 3

Hepatic PEPCK-C is required for fasting-induced reduction in energy state. Hepatic adenine nucleotides measured by HPLC in Pcklox/lox and littermate $P c k^{\text {lox/lox } A l b-c r e ~ m i c e ~(~} n=8 /$ group) following an 18-hour overnight fast. Mice were compared with fed controls. Hepatic AMP/ ATP ratios for each group is shown on right. Data are presented as mean \pm SEM. ${ }^{*} P<0.05$ compared with fed $P c k$ lox/lox mice. 

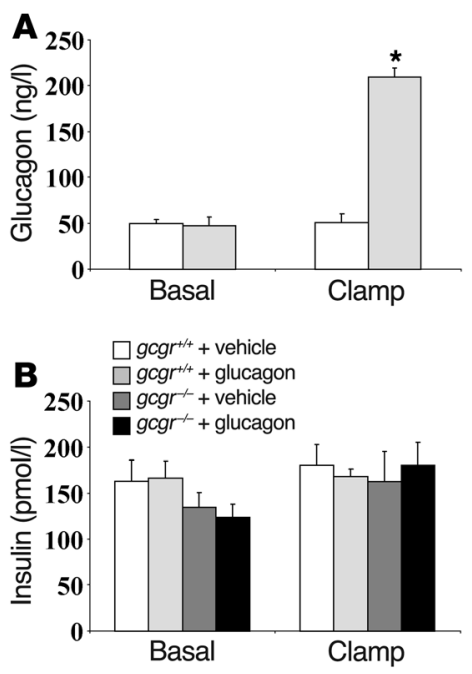

Figure 4

The hyperglucagonemic-euglycemic clamp protocol permits an increment in glucagon levels without hyperglycemia or hyperinsulinemia. (A) Plasma glucagon, (B) plasma insulin, (C) blood glucose, and (D) GIR in 5-hour-fasted, 12-week-old $\mathrm{Gcgr}^{+/+}$and $\mathrm{Gcgr}^{-/}$littermate mice on a C57BL/6 background during a hyperglucagonemic-euglycemic clamp ( $n=7-9 / g r o u p)$. At -60 minutes (equilibration), mice were infused with phloridzin $(80 \mu \mathrm{g} / \mathrm{kg} / \mathrm{min})$ and a variable GIR to achieve and maintain euglycemia $(\sim 8.5 \mathrm{mmol} / \mathrm{l})$. At 0 minutes, glucagon $(10 \mathrm{ng} / \mathrm{kg} / \mathrm{min})$ was infused during a 120 -minute experimental period. Blood glucose was measured every 5 minutes during equilibration and every 10 minutes during the experimental period. Basal glucose and hormone levels are the mean \pm SEM of samples taken at -15 and $-5 \mathrm{~min}$. Clamp hormones are the mean \pm SEM of samples taken at 100 and 120 minutes. ${ }^{*} P<0.05$ compared with $\mathrm{Gcgr}^{+/+}$vehicle-injected control mice.

$(P<0.05)$. In $\mathrm{Gcgr}^{-/}$mice, adenine nucleotides were unchanged (Figure 5A) and the hepatic energy charge was $0.73 \pm 0.04$ and $0.71 \pm 0.02$ in vehicle- and glucagon-infused mice, respectively. Elevated glucagon in $\mathrm{Gcgr}^{+/+}$mice reduced the exogenous glucose requirement to maintain euglycemia (Figure 5B), due to increased hepatic glucose output and greater glycogen breakdown (Figure 5C) compared with vehicle-infused $\mathrm{Gcgr}^{+/+}$control mice. The glucose requirement was higher in $\mathrm{Gcgr}^{-1}$ - mice, but the glucagon infusion had no effect (Figure 5B). Urine glucose exceeded $27 \mathrm{mmol} / \mathrm{l}$ in each group, indicating a potent inhibition of renal glucose reuptake by phloridzin. There were no significant changes in hematocrit or catecholamines (Supplemental Figure 1), indicating that mice were unstressed during the clamp.

Increased AMP and decreased ATP levels in $\mathrm{Gcgr}^{+/+}$mouse livers infused with glucagon corresponded to increased phosphorylation of total AMPKa (Figure 5D) due to increased phosphorylation of both $\alpha 1$ and $\alpha 2$ isoforms (Figure 5, E and F). A downstream target of AMPK, acetyl-CoA carboxylase (ACC), also showed increased phosphorylation in the liver (Figure 5G). Increased AMP/ATP ratios in glucagon-infused $\mathrm{Gcgr}^{+/+}$mouse liver also corresponded to increased PEPCK-C protein content (Figure 5F). In contrast, phosphorylation of AMPK $\alpha$ and ACC as well as total PEPCK-C protein content were unchanged in $\mathrm{Gcgr}^{-1}$ mice infused with glucagon or vehicle (Figure 5, D-F). Total AMPK $\alpha$, ACC, and PEPCK-C protein es in $P c k^{l o x} / l o x$ mice corresponded to increased hepatic AMP/ATP ratios (Figure 7A) and an energy charge of $0.32 \pm 0.04$ ( $P<0.05$ vs. vehicle-infused $P c k^{l o x} / / 0 x$ mice). Glucagon had no effect in $P c k^{l o x} / l o x \mathrm{Alb}-c r e$ to induce changes in hepatic adenine nucleotides (Figure 7A).

Increased AMP and decreased ATP levels in Pck ${ }^{l o x} / 10 x$ mouse livers infused with glucagon corresponded to increased phosphorylation of total AMPK $\alpha$, phosphorylation of its downstream target, ACC, and increased PEPCK-C protein content (Figure 7, B-D). In contrast, phosphorylation of AMPK $\alpha$ and ACC was unchanged in $P c k^{l o x} /$ lox $\mathrm{Alb}$-cre mice infused with glucagon or vehicle (Figure 7, B and C). Neither AMPK $\alpha$ nor ACC protein content differed between genotypes. There was also no change in the phosphorylation status or total protein content of LKB1 in any group (Figure 7E).

The link between hepatic PEPCK-C protein and energy state was further defined by determining the correlation between changes in protein content and hepatic AMP/ATP ratios in mice subjected to metabolic stressors and hyperglucagonemic-euglycemic clamps. As shown in Figure 7F, this correlation is $r=0.63$.

\section{Discussion}

The goal of these studies was to define the physiological regulation of the hepatic energy state. This is a fundamental issue in metabolic regulation because adenine nucleotides, which define the energy state, are critically coupled to energetic processes and 

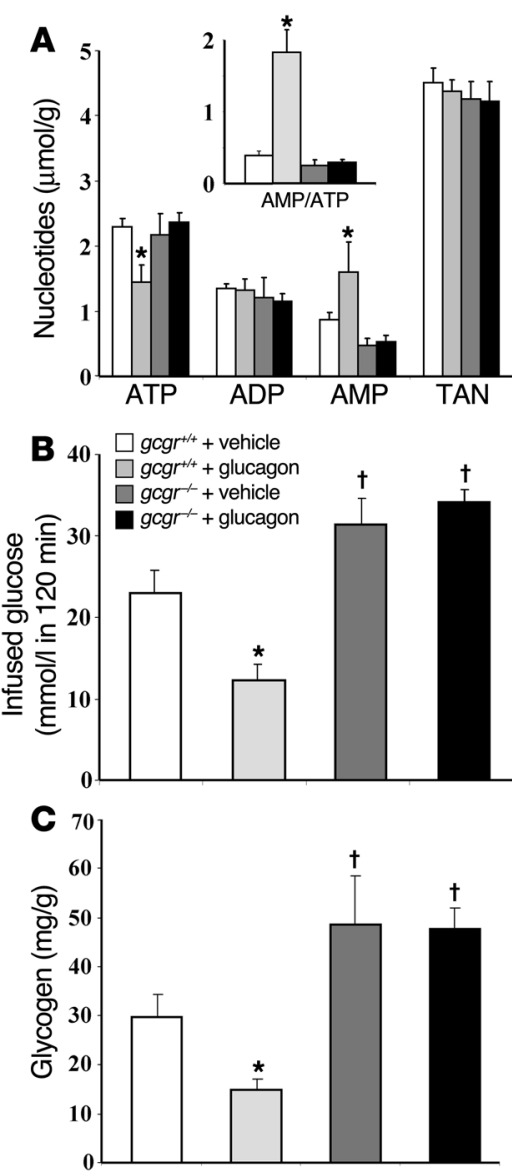

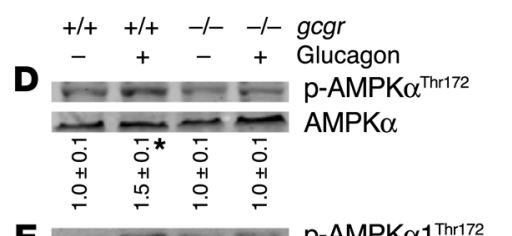

E

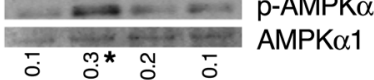

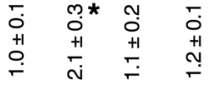

$\mathbf{F}$

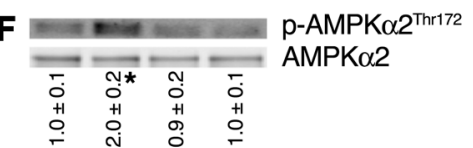

G

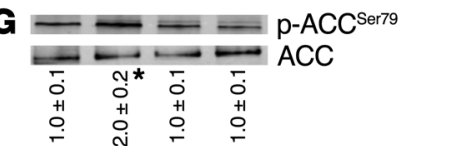

H

$\underset{\overline{0}}{\overline{0}} \overline{\sigma_{-}}$PEPCK-C

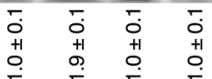

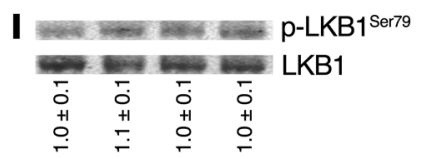

Figure 5

Glucagon lowers the hepatic energy state sufficient to activate AMPK. (A) Hepatic adenine nucleotides measured by HPLC, (B) total glucose infused, and (C) hepatic glycogen in 5-hour-fasted 12-week-old Gcgrt/+ and $\mathrm{Gcgr}^{-1}$ littermate mice on a C57BL/6 background following a hyperglucagonemic-euglycemic clamp ( $n=7-9$ /group). Hepatic AMP/ATP ratios are shown for each group in the inset of A. (D-I) Representa-

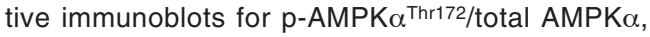

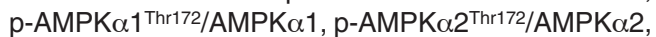
p-ACCSer79/ACC, PEPCK-C, and p-LKB1 Ser428/LKB1 content. All blots are normalized to GAPDH. Data are mean \pm SEM. The numbers beneath each lane are arbitrary units normalized to vehicle-infused $\mathrm{Gcgr}^{+/+}$ mice. ${ }^{\star} P<0.05$ compared with all other groups. t $P<0.05$ compared with $\mathrm{Gcgr}^{+/+}$mice. modulate key regulatory enzymes (e.g., AMPK). Moreover, metabolic pathways in the liver are a hub for whole-body metabolism, and regulatory changes linked to alterations in the hepatic energy state have potentially robust consequences in health and disease. In order to examine the site(s) involved in the regulation of the hepatic energy state, it was necessary to develop a well-controlled model system in which liver metabolism could be studied in vivo. Isolated hepatocytes and perfused liver preparations are valuable model systems. However, they are disruptive to the energy state and require an artificially high oxygen content (usually 95\% $\mathrm{O}_{2}$ ) to use. This obviated their utility in the current study. Our current findings show that (a) a number of physiological metabolic stressors induce the transition to a hepatic energy-depleted state; (b) hepatic glucagon action and associated flux through PEPCK-C are critical in mediating the stress-induced transition to a hepatic energy-depleted state; and (c) glucagon action amplifies AMPK signaling in the liver through a mechanism that is independent of increased LKB1 activation.

Experiments testing the effect(s) of fasting, exercise, hypoglycemia, diabetes, and a high-fat diet in C57BL/6 mice demonstrate that the transition to a hepatic energy-depleted state occurs across a range of metabolic stressors. These comprehensive results illustrate that adenine nucleotides in the mouse liver are highly sensitive to acute physiological stressors as well as metabolic disease and that changes are not solely isolated to exercise. These findings are important because the magnitude of the changes in hepatic energy state suggests that regulatory consequences are likely, considering the coupling of adenine nucleotides to metabolic pathways in the liver (1). This notion is reinforced by findings that hepatic AMPK phosphorylation is increased following exercise $(11,33,34)$ and fasting $(34,35)$. The existing literature on changes in liver adenine nucleotides in response to metabolic stressors is difficult to interpret $(22,36-43)$. Previous studies in rats have generally reported stress-induced reductions in hepatic ATP (36-43), although one study found that this did not occur in response to varying fast durations (22). A number of these earlier studies have also shown that hepatic AMP levels increase in response to stress $(22,36,37,41)$, while others have reported no change $(42,43)$. Many of these earlier studies do not report ADP and/or AMP levels (38-40), estimate adenine nucleotide concentrations using enzymatic methods (22, 36-40, 42, 43), or report reductions in TAN (41), thus complicating a full assessment of the energy state. The current findings, which used HPLC to measure adenine nucleotides, are therefore valuable to show that physiological stress conditions do indeed provoke changes in adenine nucleotides corresponding to a reduced energy state. Changes are characterized by decreases in ATP, no change in ADP, and increases in AMP, such that TAN does not vary. It is important to note that the adenine nucleotide levels reported in the present study are consistent with other data in the mouse (44, 45). It is also unlikely that any of the observed differences are due to tissue handling or analytical differences because the control and experimental groups were studied contemporaneously.

The present studies focusing on adenine nucleotides in the liver also show that changes in response to metabolic stress are in marked contrast to that which occurs in skeletal muscle. This is particularly surprising during exercise because skeletal muscle is 
A
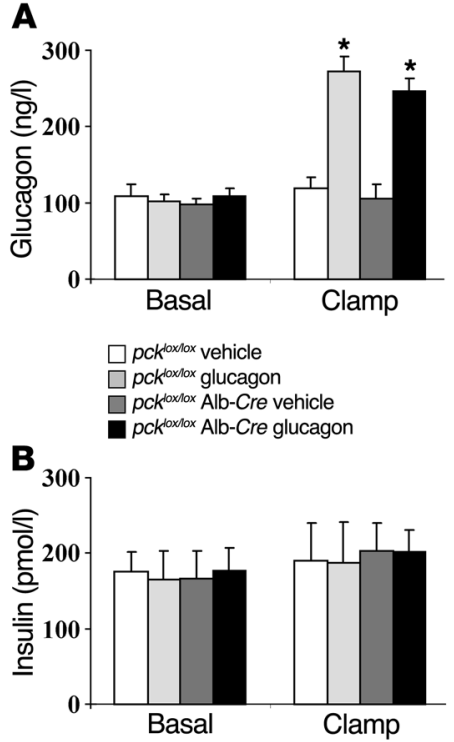

C

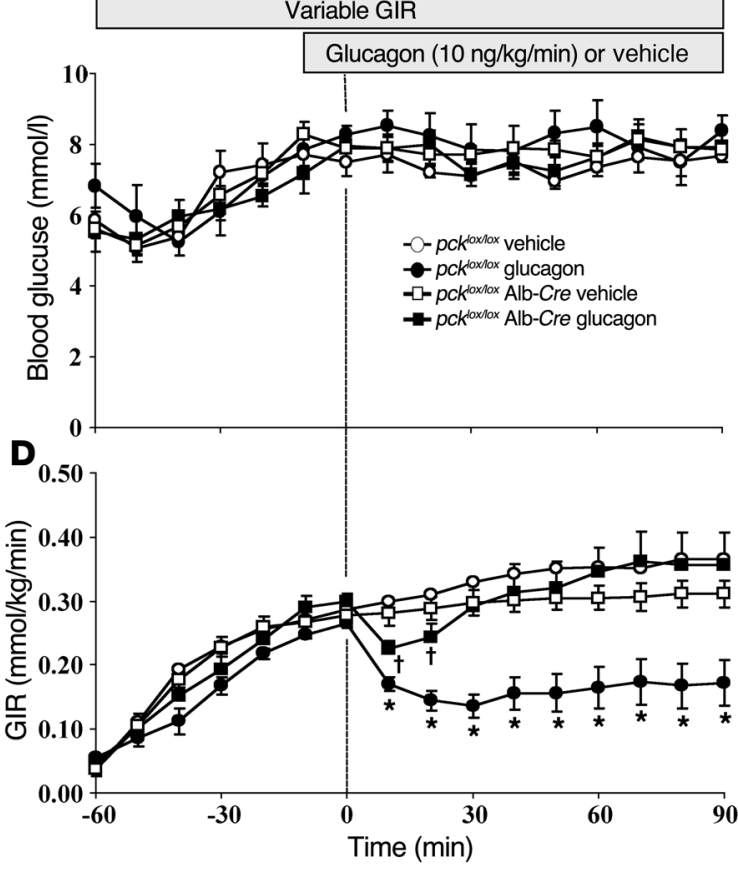

\section{Figure 6}

Liver-specific deletion of PEPCK-C blunts the effect of glucagon during a hyperglucagonemic-euglycemic clamp. (A) Plasma glucagon, (B) plasma insulin, (C) blood glucose, and (D) GIR in 5-hour-fasted,

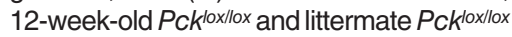
Alb-cre mice during a hyperglucagonemiceuglycemic clamp ( $n=7-9 /$ group). At -60 min (equilibration), mice were infused with phloridzin $(80 \mu \mathrm{g} / \mathrm{kg} / \mathrm{min})$ and a variable GIR to achieve and maintain euglycemia $(\sim 8.0 \mathrm{mmol} / \mathrm{l})$. At 0 minutes, glucagon (10 $\mathrm{ng} / \mathrm{kg} / \mathrm{min}$ ) was infused during a $90-\mathrm{min}-$ ute experimental period. Blood glucose was measured every 5 minutes during equilibration and every 10 minutes during the experimental period. Basal glucose and hormone levels are the mean \pm SEM of samples taken at -15 and -5 minutes. Clamp hormones are the mean \pm SEM of samples taken at 70 and 90 minutes. ${ }^{*} P<0.05$ compared with $P c k^{\text {lox/lox }}$ vehicle control mice. performing exhaustive work and AMPK is activated under these circumstances $(46,47)$. This finding is, however, consistent with the results of a previous study (11). The multifaceted metabolic roles of the liver and the absence of creatine kinase may underlie these contrasting effects. Measurement of skeletal muscle adenine nucleotides is important because they provide further support that results in the liver are not artifacts of anoxia due to technical issues. Anoxia has been previously shown to alter hepatic adenine nucleotides in a manner consistent with a lowered energy state (48). Skeletal muscle is also prone to anoxia, and this condition would reduce the energy state. Skeletal muscle was removed after the liver in each experiment, and adenine nucleotides deviated little, if any, in response to a variety of conditions and a variety of models.

Glucagon action was considered a mechanism to explain changes in the hepatic energy state based on independent evidence that glucagon levels rise during metabolic stress (17-24), activate $\operatorname{AMPK}(25,26)$, and potently stimulate energy-requiring processes in the liver $(27-29,49)$. Glucagon binding to its receptor increases adenosine cAMP levels in the liver, leading to stimulation of PKA activity. PKA triggers numerous metabolic changes in the liver, including acute effects to increase glycogen breakdown and stimulate gluconeogenic flux through PEPCK-C. These combined pathways represent the canonical actions of glucagon to increase hepatic glucose production (49). Glucagon action is, however, also shown to stimulate metabolic pathways in the liver, such as fat oxidation and ureagenesis, which are fundamental to fueling gluconeogenesis in the liver (27-29). Energetic requirements of gluconeogenesis and activation of substrates in the liver are proposed to underlie reductions in the energy state because several steps in these interrelated processes require hydrolysis of ATP to ADP. AMP and ATP levels in the liver would rise and fall, respectively, due to adenylate kinase activity (2 ADP converted to 1 ATP and 1 AMP), thus lowering the energy state (50). Activation of fatty acids and amino acids in the liver also entails hydrolysis of ATP to AMP, thus directly reducing the energy state. Studies in adipocytes suggest that epinephrine and exercise provoke dramatic changes in adenine nucleotides that activate $\operatorname{AMPK}(51,52)$. Such effects were blocked in isolated adipocytes when acetyl-CoA synthetase, the enzyme required to activate fatty acids, was inhibited, suggesting that this step lowers the energy state (51). The fact that ADP levels do not vary in the current physiological perturbations also suggests that oxidative uncoupling in the mitochondria does not contribute to changes in the energy state.

The requirement for glucagon receptor activation to provoke hepatic energy depletion was first examined using acute metabolic stressors in mice lacking the glucagon receptor. Remarkably, in $\mathrm{Gcgr}^{-1}$ mice, the exercise-induced hepatic energy-depleted state was abolished and the response to fasting was largely attenuated compared with $\mathrm{Gcgr}^{+/+}$littermates. Gcgr/- mice have a complicated phenotype, including reduced blood glucose, lower insulin, supraphysiological levels of glucagon, and diminished hepatic fat oxidation $(26,31) . \mathrm{Gcgr}^{-}$- mice do, however, retain the capacity to increase cAMP levels in response to epinephrine (31), suggesting that the limited or absent changes in the energy state following metabolic stress is due to loss of the receptor rather than defective pathways in the liver. The action of glucagon to lower the hepatic energy state was further supported by hypoglycemic clamp results in $129 \mathrm{X} 1 / \mathrm{Sv}$ mice. In this strain, the blunted glucagon response to hypoglycemia was associated with a higher hepatic energy state compared with C57BL/6 mice, which showed a marked glucagon response and lowered hepatic energy state (30). Taken together, these findings suggest that factors other than glucagon have a limited role in mediating the transition to a hepatic energy-depleted state. Moreover, these results provide in vivo evidence using 2 different model systems, demonstrating that changes in the hepatic energy state are mediated by glucagon receptor activation in the liver. 

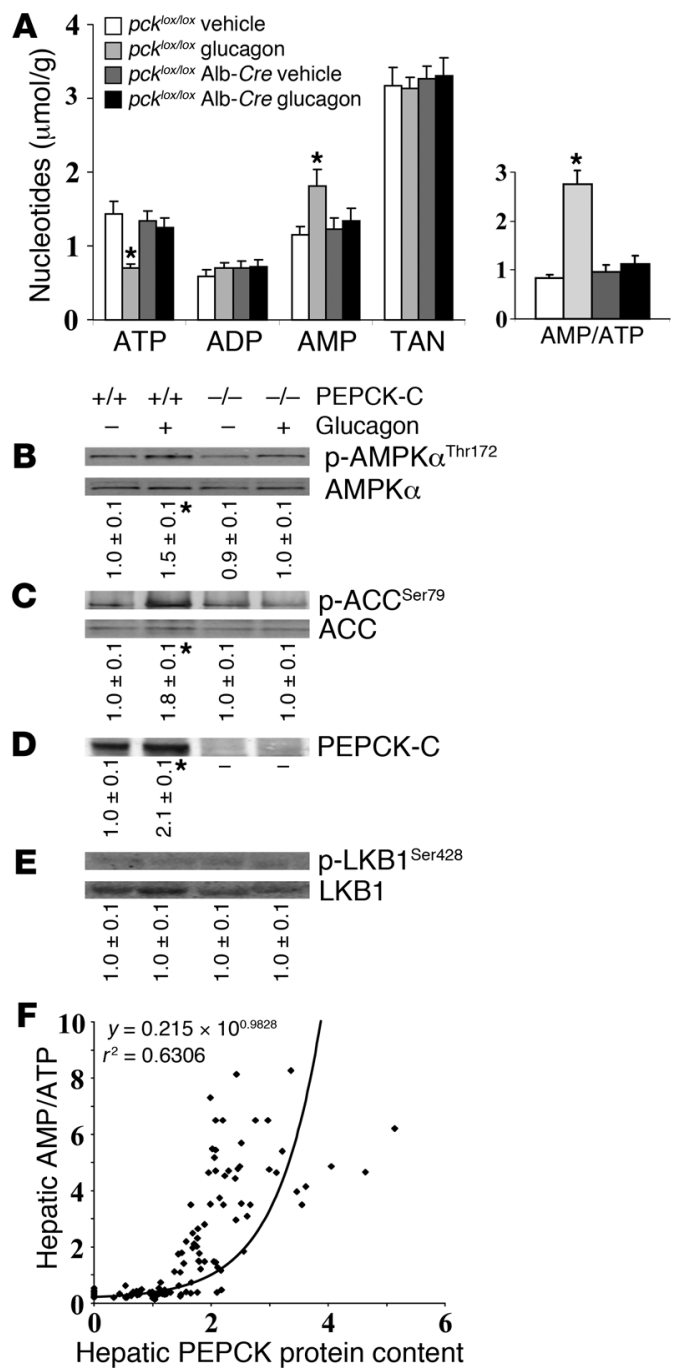

The action of glucagon to induce changes in the hepatic energy state was isolated in these studies using what is to our knowledge a novel hyperglucagonemic-euglycemic clamp. This powerful in vivo technique permits a selective increase in glucagon to physiological levels without increases in blood glucose and insulin. This is critical to fully define the sensitivity of hepatic glucagon receptor activation. This technique was first performed in $\mathrm{Gcgr} r^{+/}$mice to isolate the effect of glucagon on adenine nucleotides. Gcgr/- mice were also studied to validate that the clamp technique had no effects other than glucagon receptor activation. In $\mathrm{Gcgr}^{+/+}$mice, clamp glucagon was successfully increased to levels observed in mice performing maximal treadmill exercise (18). The elevation in glucagon during the clamp in $\mathrm{Gcgr}^{+/+}$mice corresponded to greater stimulation of liver metabolism based on increased glycogen breakdown and a lower GIR requirement to maintain target glycemic levels compared with vehicle-infused $\mathrm{Gcgr}^{+/+}$mice. Stimulation of liver metabolism by glucagon in $\mathrm{Gcgr}^{+/+}$mice was indeed linked to a lower hepatic energy state. Increased hepatic AMP/ATP ratios corresponded to increased total PEPCK-C protein content as well as greater phosphorylation of AMPK, indicative of increased enzyme activity. Phosphorylation of ACC, a downstream target of AMPK critically involved in regulating fat oxidation, was also increased in $\mathrm{Gcgr}^{+/+}$

\section{Figure 7}

Hepatic PEPCK-C is required to mediate metabolic stress- and glucagon-induced reductions in hepatic energy state. (A) Hepatic adenine nucleotides measured by HPLC in 5-hour-fasted 12-week-old Pcklox/lox and littermate $P c k^{10 x / l o x}$ Alb-cre mice following a hyperglucagonemiceuglycemic clamp ( $n=7-9 /$ group). Hepatic AMP/ATP ratios are shown for each group on the right. (B-E) Representative immunob-

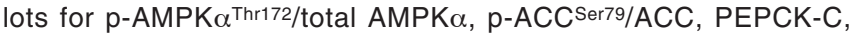
and $p$-LKB1 Ser428/LKB1 content. The numbers beneath each lane are arbitrary units normalized to vehicle-infused $P c k^{10 x / l o x} \mathrm{Alb}-c r e$ mice. (F) Hepatic PEPCK-C protein content relative to hepatic AMP/ATP ratios in mice from all metabolic stress and/or clamp conditions in C57BL/6, 129X1/Sv, Gcgr ${ }^{+/+}, \mathrm{Gcgr}^{-1}$, Pcklox/lox , and Pcklox/lox Alb-cre mice. PEPCK-C protein content was determined by immunoblot and normalized to C57BL/6 mice in the fed state. Data are mean \pm SEM. ${ }^{*} P<0.05$ compared with all other groups.

mice, further supporting increased AMPK activity due to elevated glucagon levels. Increased glucagon did not, however, correspond to changes in LKB1 activation, suggesting that changes in AMPK were not strictly due to activity of this upstream kinase, as previously suggested from a study conducted in vitro (25). As expected, glucagon had no effect on the hepatic energy state in $\mathrm{Gcgr}^{-/}$ mice. There were also no differences in hepatic p-AMPK ${ }^{\mathrm{Thr}} 172 /$ AMPK, p-ACC Ser79/ACC, and PEPCK-C between Gcgr-/- mice and vehicle-infused $\mathrm{Gcgr}^{+/+}$mice, indicating that loss of that specific receptor was responsible for effects observed in response to fasting and exercise in $\mathrm{Gcgr}^{-/}$mice. Insulin did tend to increase during the clamp in $\mathrm{Gcgr}^{-/}$mice, but these levels were appropriate for the increase in blood glucose.

The hypothesis that glucagon action mediates the transition to a hepatic energy-depleted state was further refined using mice with liver-specific deletion of PEPCK-C. As previously noted, glucagon action is well characterized to stimulate gluconeogenesis via increased substrate flux through PEPCK-C. This capacity of the liver to produce glucose de novo results in a net loss of ATP and is critically linked to additional processes that require energy. It is important to note that $P c k^{l o x} /$ lox $\mathrm{Alb}$-cre mice are a complex genetic mouse model that maintains near normal blood glucose despite the absence of this key gluconeogenic enzyme (53-55). Liver-specific deletion of PEPCK-C results in hepatic lipid accumulation and diminished TCA cycle flux indicative of an altered energetic phenotype. This is a highly valuable mouse model in the current studies because the genetic manipulation is liver specific, and sophisticated metabolic flux analyses by Burgess and colleagues have shown in great detail that PEPCK-C-mediated gluconeogenesis is coupled to oxidative and anapleurotic processes $(53,54)$, which are key in maintaining a hepatic energy state. In these mice, the hepatic energy state was preserved in response to an overnight fast, supporting the notion that PEPCK-C-mediated gluconeogenesis is needed to induce changes in the energy state. Hyperglucagonemiceuglycemic clamp results further clarify a critical role for PEPCK-C to mediate the glucagon-induced transition to a hepatic energydepleted state and offer further mechanistic insight. This is based on findings that elevated glucagon levels fail to alter hepatic adenine nucleotides in mice with liver-specific deletion of PEPCK-C. The phosphorylation status of LKB1, AMPK, and ACC were also

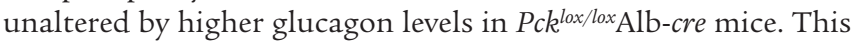
finding again suggests that energetic changes in the liver, resulting in increased AMP-mediated allosteric effects, lead to activation 
of AMPK rather than a direct pathway involving PKA-mediated covalent modification of LKB1 (25). Our results, which indicate that allosteric modulation of AMPK by adenine nucleotides is the principal regulatory event, are strengthened by evidence that LKB1 is a constitutively active upstream kinase $(56,57)$. Additional data show that binding of AMP to AMPK increases enzyme activity by inhibiting dephosphorylation (58-60).

Taken together, the present study defines an important metabolic pathway whereby glucagon receptor activation and subsequent stimulation of gluconeogenic flux through PEPCK-C induce a lowered hepatic energy state sufficient to activate AMPK in the liver. A modest positive correlation was found between hepatic PEPCK-C protein content and changes in AMP/ATP ratios. These results support a link between the energetics of gluconeogenesis and associated pathways (i.e., substrate activation steps) and change in hepatic energy state. This link is also supported by a recent study, which found that adenoviral-mediated silencing of PEPCK-C in $d b / d b$ mice lowered hepatic glucose production and improved hepatic energy status (45). It is important to note that all studies were done in vivo using genetically modified mice and what we believe is a novel clamp protocol to isolate the physiology of glucagon, the glucagon receptor, and PEPCK-C. While each approach may have inherent limitations, all findings converge on the conclusion that glucagon receptor activation leads to a lowered hepatic energy state. These studies also add to the concept of AMPK as a metabolic sensor sensitive to changes in AMP/ATP ratios. These data are noteworthy because few studies focusing on AMPK in the liver have actually measured adenine nucleotides. We propose that the fall in hepatic energy state during acute metabolic stressors is a normal physiological response mediated by glucagon receptor signaling, in which AMPK is stimulated in an orchestrated adaptive effort to increase energy production in the liver.

It is important to consider that glucagon-stimulated changes to lower the hepatic energy state and activate AMPK also likely have long-term transcriptional consequences. This notion is based on strong evidence that AMPK regulates a wide range of transcriptional processes (61). Low hepatic energy levels have also been recently linked to a pathway involving $\mathrm{NAD}^{+}$-dependent sirtuin 1 mediated (SIRT1-mediated) deacetylation of PPAR $\gamma$ coactivator $1 \alpha$ (PGC1 $\alpha$ ) and expression of forkhead box O1 (FOXO1) (62). This pathway has been extended in myocytes to show an interplay between AMPK and SIRT1 to modulate the FOXO family of transcription factors and PGC1 $\alpha$-dependent genes involved in mitochondrial and lipid metabolism (63). In support of our view that changes in adenine nucleotides have a profound regulatory impact, Cantó et al. (63) have proposed that changes in AMP/ATP ratios are the initial metabolic signal triggering transcriptional changes. Similar effects in the liver might contribute to attenuation of exercise-induced reductions in hepatic AMP following long-term training (40) and/or improved efficiency with which the liver converts gluconeogenic substrate into glucose following glucagon stimulation $(64,65)$. An additional study has, however, dissociated the role of SIRT1 from modulation of PGC1 $\alpha$-dependent genes in vivo in skeletal muscle and heart (66). Future studies are needed to elucidate key components of this pathway and clarify its role in the liver.

An additional important finding is that the hepatic energy state is lowered in high-fat diet-fed and diabetic mice that are not acutely stressed. This suggests that high AMP/ATP levels are part of the metabolic disease milieu, which is consistent with evidence in obese humans showing that hepatic ATP levels are reduced (67, 68). It is noteworthy in this context that ADP was reduced and AMP increased to levels inconsistent with the energetics of adenylate kinase and activation of substrate that have been proposed to mediate the changes seen in response to physiological stress $(1,8$, 51). These observations suggest the possibility that hepatic mitochondrial dysfunction (69), hypoxia (70), or additional impairments underlie a lowered energy state in metabolic disease. In addition, if the increase in hepatic AMP/ATP ratios in metabolic disease corresponds to activation of AMPK, then the characteristic development of fatty liver is a paradox. An alternative is that the sensitivity of AMPK to AMP/ATP ratios is diminished in metabolic disease. This notion is supported by recent evidence in ethanol-fed rat liver (71) and the fact that AMPK is not activated by exercise in skeletal muscle of obese individuals with and without type 2 diabetes (72). This finding has therapeutic implications, as AMPK, the glucagon receptor, and PEPCK-C are current or proposed drug targets $(45,49,73)$. It is currently unknown whether these interventions would affect AMPK sensitivity to the energy state or downstream AMPK targets. In summary, these studies extend our understanding of metabolic control in the liver to include significant changes in the energy state and provide a more precise understanding of how the liver regulates substrate metabolism.

\section{Methods}

\section{Animals}

All procedures were approved by the Vanderbilt University Animal Care and Use Committee. C57BL/6 and 129X1/Sv mice were from The Jackson Laboratory. Mice with global deletion of the glucagon receptor ( $\left.\mathrm{Gcgr}^{--}\right)$and wild-type littermates $\left(\mathrm{Gcgr}^{+/+}\right)$were on a C57BL/6 background. Gcgr ${ }^{/-}$mice have supraphysiological glucagon levels and reduced blood glucose, leptin, and adiposity compared with $\mathrm{Gcgr}^{+/+}$mice (31). Insulin, body weight, food intake, and energy expenditure are similar between genotypes (31). Mice with a liver-specific deletion of cytosolic PEPCK (Pck) driven by the albumin-cre transgene (Pck $k^{l o x} / l o x$ Alb-cre) and wild-type littermates $\left(P c k^{l o x} / l o x\right)$ were also used. $P c k^{l o x} / l o x \mathrm{Alb}-\mathrm{cre}$ mice retain normal fed and fasting blood glucose but have higher fasting plasma free fatty acid levels and lipid accumulation in the liver compared with $P c k^{l o x} / / o x$ mice (55). All experiments used mice at 12 weeks of age. Mice were housed in a temperature-controlled environment on a 12-hour light/12-hour dark cycle and fed either a chow diet (5\% fat) or high-fat diet (60\% fat) ad libitum.

\section{Surgical procedures}

Previously described surgical techniques were used $(30,74)$. Carotid artery and jugular vein catheters were implanted for sampling and infusing, respectively, 5 days prior to study. Only mice that returned to within $10 \%$ of pre-surgical body weight were studied.

\section{Metabolic experiments}

Hepatic adenine nucleotides were measured in all protocols. Adenine nucleotides in gastrocnemius were determined in select groups. In hypoglycemic and hyperglucagonemic-euglycemic clamp protocols, mice were placed in a 1-liter plastic tub lined with bedding to begin a 5 -hour fast at $8 \mathrm{am}$. Catheter lines were attached to a swivel 60 minutes prior to the first infusion. Mice were unrestrained and not handled thereafter to minimize stress.

Fasting for 5 and 18 hours. C57BL/6 mice were euthanized after 5-hour morning fasts and 18-hour overnight fasts. Fed controls had access to food. In separate experiments, Gcgr ${ }^{+/+}$and Gcgr $r^{-/}$as well as Pcklox/lox and $P c k^{l o x} /$ ox Alb-cre mice were fasted for 18 hours or given access to food. 
Maximum exercise. Male $\mathrm{Gcgr}^{+/+}$and $\mathrm{Gcgr}^{-/}$mice were acclimated to treadmill exercise (Columbus Instruments) 2 days prior to study, with $10 \mathrm{~min}$ utes of exercise at $10 \mathrm{~m} / \mathrm{min}$. On the day of study, after a 5-hour morning fast, $\mathrm{Gcgr}^{+/+}$and $\mathrm{Gcgr}^{-/}$littermate mice either ran until exhaustion or were placed on the unmoving treadmill for 30 minutes. The exercise protocol was a speed of $10 \mathrm{~m} / \mathrm{min}$ at 0 minutes and increased $4 \mathrm{~m} / \mathrm{min}$ every 3 minutes until exhaustion. Exhaustion was defined by mice remaining on a shock grid at the end of the treadmill $(1.5 \mathrm{~mA}, 200-\mathrm{ms}$ pulses, $4 \mathrm{~Hz})$ for 5 seconds.

STZ treatment. A single i.p. injection of STZ $(150 \mathrm{mg} / \mathrm{kg}$ in $0.4 \mathrm{M}$ sodium citrate buffer, $\mathrm{pH} 7.4$ ) or citrate buffer was administered to male C57BL/6 mice. Blood glucose and body weight were measured daily for 1 week, and diabetes was defined by blood glucose levels greater than $20 \mathrm{mmol} / \mathrm{l}$.

High-fat diet. C57BL/ 6 mice were fed a high-fat or chow diet for 9 weeks after weaning. Mice were euthanized after a 5-hour fast.

Hypoglycemic clamp. Insulin (120 pmol/ kg/min) and a variable GIR were infused for 120 minutes to achieve and maintain hypoglycemia of about $2.2 \mathrm{mmol} / \mathrm{l}$ in male C57BL/6 and 129X1/Sv mice. Blood samples (250 $\mu \mathrm{l})$ were taken at $-15,30,60$, and 120 minutes to measure basal plasma glucagon, epinephrine, norepinephrine, and corticosterone and the counterregulatory response to hypoglycemia. 129X1/Sv mice have been previously shown to have a blunted response to hypoglycemia compared with C57BL/6 mice (30).

Hyperglucagonemic-englycemic clamp. The effects of glucagon are difficult to isolate without intervention due to concomitant hyperglycemia and hyperinsulinemia. The hyperglucagonemic-euglycemic clamp uses phloridzin and a variable GIR to create a background, and glucagon is infused without changes in blood glucose or insulin. At -60 minutes, phloridzin $(80 \mu \mathrm{g} / \mathrm{kg} / \mathrm{min})$ was infused to prevent renal reuptake of glucose. Salinewashed erythrocytes were infused $(5 \mu \mathrm{l} / \mathrm{min})$ to prevent a fall in hematocrit. Blood glucose $(5 \mu \mathrm{l})$ was measured every 5 minutes, and a variable GIR was infused to maintain euglycemia ( $~ 8.5 \mathrm{mmol} / \mathrm{l})$. At 0 minutes, glucagon $(10 \mathrm{ng} / \mathrm{kg} / \mathrm{min})$ was infused, and samples for blood glucose $(5 \mu \mathrm{l})$ were taken every 5 minutes. GIR was adjusted to maintain euglycemia. Basal samples for plasma insulin $(50 \mu \mathrm{l})$ and glucagon $(50 \mu \mathrm{l})$ were taken at -15 and -5 minutes. Samples for basal catecholamines $(50 \mu \mathrm{l})$ were taken at -15. Clamp hormones were sampled twice in the last 20 minutes of the clamp. Urine glucose was measured using urinalysis strips. Blood samples were collected in tubes containing EDTA and stored at $-20^{\circ} \mathrm{C}$.

\section{Analytical methods}

All mice were euthanized and livers were quickly removed in situ (within 20 seconds of euthanizing the animal), followed by gastrocnemius. Tissues were freeze-clamped and stored at $-80^{\circ} \mathrm{C}$. Adenine nucleotides were measured by HPLC in the Vanderbilt University Mouse Metabolic Phenotyping Center. Approximately $50 \mathrm{mg}$ of frozen tissue was homogenized in $500 \mu \mathrm{l} 0.4 \mathrm{M} \mathrm{HClO}_{4}$ containing $0.5 \mathrm{mM}$ EGTA and remained on ice for 10 minutes. Samples were spun at $2,900 \mathrm{~g}$ at $4^{\circ} \mathrm{C}$ for 10 minutes. The supernatant was neutralized with $0.5 \mathrm{M} \mathrm{K}_{2} \mathrm{CO}_{3}$. Samples were placed on ice for 5 minutes and spun at $2,900 \mathrm{~g}$ at $4^{\circ} \mathrm{C}$ for 10 minutes. Analysis was performed using a Supelco Supelcosil LC18-T column $(4.6 \times 250$ $\mathrm{mm}, 5-\mu \mathrm{m}$ particle size) interfaced with a Waters 490 detector $(254 \mathrm{~nm}$ at
1.0 AUFS) and a constant flow rate of $0.7 \mathrm{ml} / \mathrm{min}$. Adenine nucleotides were identified using mobile phase $\mathrm{A}\left(100 \mathrm{mM} \mathrm{KH}_{2} \mathrm{PO}_{4}, \mathrm{pH}\right.$ 6.0) for 12.5 minutes, mobile phase $\mathrm{B}$ (90:10 ratio of $100 \mathrm{mM} \mathrm{KH}_{2} \mathrm{PO}_{4} / \mathrm{MeOH}$ ) for 3.5 minutes, and mobile phase $\mathrm{A}$ for 44 minutes and quantified using known standards. Hepatic glycogen was measured as previously described (75). Total AMPK $\alpha$, AMPK $\alpha$ phosphorylated at threonine 172 (p-AMPK ${ }^{\text {Thr172), }}$

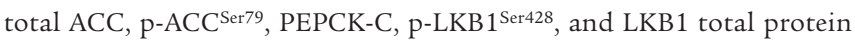
content were determined by immunoblotting. Samples were homogenized 1:10 (wt/vol) in solution containing 10\% glycerol, $50 \mathrm{mM}$ Tris $\mathrm{HCl}, 1 \mathrm{mM}$ EDTA, 1 mM EGTA, 1\% Triton X-100, 1 mM DTT, 1 mM PMSF, 50 mM $\mathrm{NaF}, 5 \mathrm{mM}$ Na-pyrophosphate, and $10 \mu \mathrm{g} / \mu \mathrm{l}$ protein inhibitor cocktail. Protein concentration was determined using a commercial protein assay (Bio-Rad). Protein $(60 \mu \mathrm{g})$ was run on an SDS-PAGE gel and transferred to a PVDF membrane. Membranes were blocked in fluorescent Western blotting buffer (Rockland Immunochemicals) and incubated with antirabbit antibodies for AMPK, ACC, and LKB1 (Cell Signaling Technology) or anti-goat antibodies for PEPCK-C (a gift of Kevin Niswender, Vanderbilt University) overnight at $4{ }^{\circ} \mathrm{C}$. Membranes were then incubated with IRDye 800 -conjugated antibodies (Rockland Immunochemicals). GAPDH was used as a loading control. Immunoblots for AMPK $\alpha 1$ and - $\alpha 2$ were performed after immunoprecipitation using $200 \mu \mathrm{g}$ of protein, $2 \mu \mathrm{g}$ of antirabbit AMPK $\alpha 1$ polyclonal antibody (Santa Cruz Biotechnology Inc.), $2 \mu 1$ of anti-rabbit AMPK $\alpha 2$ monoclonal antibody (Santa Cruz Biotechnology Inc.), and immobilized Recomb protein A beads (Pierce Biotechnology). Plasma glucagon (76), insulin (76), epinephrine (77), and norepinephrine (77) were determined by the Vanderbilt University Mouse Metabolic Phenotyping Center Hormone Assay and Analytical Resources Core.

\section{Statistics}

Total glucose requirement was assessed using the trapezoidal method. Statistical comparisons were made using 1-way ANOVA followed by Fisher's least-significant-difference test for post-hoc comparisons. Data are presented as means \pm SEM. Statistical significance was defined as $P<0.05$.

\section{Acknowledgments}

We would like to thank Wanda Snead, Bakula Trivedi, and Eric Allen in the Vanderbilt University Mouse Metabolic Phenotyping Center Hormone and Analytical Core for measuring glucagon, insulin, and catecholamines. We would also like to thank Julio Ayala for technical advice and review of the manuscript. This work was supported by NIH grants DK50277 and DK59637 (to D.H. Wasserman) and by an NIH grant to the Vanderbilt University Molecular Endocrinology Training Program.

Received for publication January 20, 2009, and accepted in revised form May 20, 2009.

Address correspondence to: Eric Berglund, Vanderbilt University Medical Center, 2200 Pierce Ave., 823 Light Hall, Nashville, Tennessee 37232, USA. Phone: (615) 343-0580; Fax: (615) 343-1065; E-mail: berglunde@gmail.com.
1. Hardie, D.G., and Hawley, S.A. 2001. AMP-activated protein kinase: the energy charge hypothesis revisited. Bioessays. 23:1112-1119.

2. Cheung, P.C., Salt, I.P., Davies, S.P., Hardie, D.G. and Carling, D. 2000. Characterization of AMP-activated protein kinase gamma-subunit isoforms and their role in AMP binding. Biochem. J. 346:659-669.

3. Cohen, P.F., and Colman, R.F. 1972. Diphosphopyridine nucleotide dependent isocitrate dehydrogenase from pig heart. Charactgerization of the active substrate and modes of regulation. Biochemistry. 11:1501-1508.

4. Ercan, N., Gannon, M.C., and Nuttall, F.Q. 1996. Allosteric regulation of liver phosphorylase a: revisited under approximated physiological conditions. Arch. Biochem. Biophys. 328:255-264.

5. Ercan-Fang, N., et al. 2002. Integrated effects of multiple modulators on human liver glycogen phosphorylase a. Am. J. Physiol. Endocrinol. Metab. 283:E29-E37.
6. Nelson, S.W., Honzatko, R.B., and Fromm, H.J. 2002. Hybrid tetramers of porcine liver fructose-1,6bisphosphatase reveal multiple pathways of allosteric inhibition. J. Biol. Chem. 277:15539-15545.

7. Hardie, D.G., Salt, I.P., Hawley, S.A., and Davies, S.P. 1999. AMP-activated protein kinase: an ultrasensitive system for monitoring cellular energy charge. Biochem. J. 338:717-722.

8. Atkinson, D.E. 1977. Cellular energy metabolism and its regulation. Academic Press. New York, New York, 
USA. 304 pp.

9. Ramaiah, A., Hathaway, J.A., and Atkinson, D.E. 1964. Adenylate as a metabolic regulator. Effect on yeast phosphofructokinase kinetics. J. Biol. Chem. 239:3619-3622.

10. Hardie, D.G., Hawley, S.A., and Scott, J.W. 2006. AMP-activated protein kinase - development of the energy sensor concept. J. Physiol. 574:7-15.

11. Camacho, R.C., et al. 2006. Energy state of the liver during short-term and exhaustive exercise in C57BL/6J mice. Am. J. Physiol. Endocrinol. Metab. 290:E405-E408.

12. Ponticos, M., et al. 1998. Dual regulation of the AMP-activated protein kinase provides a novel mechanism for the control of creatine kinase in skeletal muscle. EMBO J. 17:1688-1699.

13. Sauer, U., and Schlattner, U. 2004. Inverse metabolic engineering with phosphagen kinase systems improves the cellular energy state. Metab. Eng. 6:220-228.

14. Camacho, R.C., Lacy, D.B., James, F.D., Donahue, E.P., and Wasserman, D.H. 2005. 5-Aminoimidazole-4-carboxamide-1-beta-D-ribofuranoside renders glucose output by the liver of the dog insensitive to a pharmacological increment in insulin. $\mathrm{Am}$. J. Physiol. Endocrinol. Metab. 289:E1039-E1043.

15. Camacho, R.C., et al. 2005. Portal venous 5-aminoimidazole-4-carboxamide-1-beta-D-ribofuranoside infusion overcomes hyperinsulinemic suppression of endogenous glucose output. Diabetes. 54:373-382.

16. Pencek, R.R., et al. 2005. 5-Aminoimidazole-4-carboxamide-1-beta-D-ribofuranoside causes acute hepatic insulin resistance in vivo. Diabetes. 54:355-360.

17. Alford, F.P., Zimmet, P., Chisholm, D.J., and Whitehouse, S. 1983. Influence of obesity on basal glucagon levels in non-diabetic and diabetic Nauruans. Clin. Endocrinol. (Oxf.). 19:721-725.

18. Fueger, P.T., et al. 2007. Glucose kinetics and exercise tolerance in mice lacking the GLUT4 glucose transporter. J. Physiol. 582:801-812.

19. Galbo, H., Holst, J.J., and Christensen, N.J. 1975. Glucagon and plasma catecholamine responses to graded and prolonged exercise in man. J. Appl. Physiol. 38:70-76.

20. Gerich, J.E., et al. 1974. Characterization of the glucagon response to hypoglycemia in man. J. Clin. Endocrinol. Metab. 38:77-82.

21. Marliss, E.B., Aoki, T.T., Unger, R.H., Soeldner, J.S., and Cahill, G.F., Jr. 1970. Glucagon levels and metabolic effects in fasting man. J. Clin. Invest. 49:2256-2270.

22. Seitz, H.J., Muller, M.J., Krone, W., and Tarnowski, W. 1977. Coordinate control of intermediary metabolism in rat liver by the insulin/glucagon ratio during starvation and after glucose refeeding. Regulatory significance of long-chain acyl-CoA and cyclic AMP. Arch. Biochem. Biophys. 183:647-663.

23. Starke, A.A., Erhardt, G., Berger, M., and Zimmermann, H. 1984. Elevated pancreatic glucagon in obesity. Diabetes. 33:277-280.

24. Unger, R.H., and Orci, L. 1976. Physiology and pathophysiology of glucagon. Physiol. Rev. 56:778-826.

25. Kimball, S.R., Siegfried, B.A., and Jefferson, L.S. 2004. Glucagon represses signaling through the mammalian target of rapamycin in rat liver by activating AMP-activated protein kinase. J. Biol. Chem 279:54103-54109.

26. Longuet, C., et al. 2008. The glucagon receptor is required for the adaptive metabolic response to fasting. Cell Metab. 8:359-371.

27. Krishna, M.G., et al. 2000. Glucagon response to exercise is critical for accelerated hepatic glutamine metabolism and nitrogen disposal. Am. J. Physiol. Endocrinol. Metab. 279:E638-E645.

28. Wasserman, D.H., Lacy, D.B., Goldstein, R.E., Williams, P.E., and Cherrington, A.D. 1989. Exerciseinduced fall in insulin and increase in fat metabolism during prolonged muscular work. Diabetes.
38:484-490.

29. Wasserman, D.H., et al. 1989. Glucagon is a primary controller of hepatic glycogenolysis and gluconeogenesis during muscular work. Am. J. Physiol. 257:E108-E117.

30. Berglund, E.D., et al. 2008. Glucose metabolism in vivo in four commonly used inbred mouse strains. Diabetes. 57:1790-1799.

31. Gelling, R.W., et al. 2003. Lower blood glucose, hyperglucagonemia, and pancreatic alpha cell hyperplasia in glucagon receptor knockout mice. Proc. Natl. Acad. Sci. U. S. A. 100:1438-1443.

32. Hawley, S.A., et al. 2003. Complexes between the LKB1 tumor suppressor, STRAD alpha/beta and MO25 alpha/beta are upstream kinases in the AMP-activated protein kinase cascade. J. Biol. 2:28.

33. Carlson, C.L., and Winder, W.W. 1999. Liver AMPactivated protein kinase and acetyl-CoA carboxylase during and after exercise. J. Appl. Physiol. 86:669-674.

34. Witters, L.A., and Kemp, B.E. 1992. Insulin activation of acetyl-CoA carboxylase accompanied by inhibition of the 5'-AMP-activated protein kinase. J. Biol. Chem. 267:2864-2867.

35. Munday, M.R., Milic, M.R., Takhar, S., Holness, M.J., and Sugden, M.C. 1991. The short-term regulation of hepatic acetyl-CoA carboxylase during starvation and re-feeding in the rat. Biochem. J. 280:733-737.

36. Bravo, C., et al. 2001. Metabolic changes induced by cold stress in rat liver mitochondria. J. Bioenerg. Biomembr. 33:289-301.

37. Dohm, G.L., and Newsholme, E.A. 1983. Metabolic control of hepatic gluconeogenesis during exercise. Biochem. J. 212:633-639.

38. Ghanbari-Niaki, A., Bergeron, R., Latour, M.G., and Lavoie, J.M. 1999. Effects of physical exercise on liver ATP levels in fasted and phosphate-injected rats. Arch. Physiol. Biochem. 107:393-402.

39. Ghanbari-Niaki, A., Desy, F., and Lavoie, J.M. 1999. Effects of phosphate injection on metabolic and hormonal responses to exercise in fructose-injected rats. Physiol. Behav. 67:747-752.

40. Houghton, C.R., Hawkins, R.A., Williamson, D.H., and Krebs, H.A. 1971. The effects of physical training on the metabolic response to short-term severe exercise in the rat. Biochem. J. 124:57P.

41. Mikami, T., and Kitagawa, J. 2006. Intense exercise induces the degradation of adenine nucleotide and purine nucleotide synthesis via de novo pathway in the rat liver. Eur. J. Appl. Physiol. 96:543-550.

42. Start, C., and Newsholme, E.A. 1968. The effects of starvation and alloxan-diabetes on the contents of citrate and other metabolic intermediates in rat liver. Biochem. J. 107:411-415.

43. Williamson, D.H., Veloso, D., Ellington, E.V., and Krebs, H.A. 1969. Changes in the concentrations of hepatic metabolites on administration of dihydroxyacetone or glycerol to starved rats and their relationship to the control of ketogenesis. Biochem. J. 114:575-584.

44. Burgess, S.C., et al. 2006. Diminished hepatic gluconeogenesis via defects in tricarboxylic acid cycle flux in peroxisome proliferator-activated receptor gamma coactivator-1alpha (PGC-1alpha)-deficien mice. J. Biol. Chem. 281:19000-19008.

45. Gomez-Valades, A.G., et al. 2008. Pck1 gene silencing in the liver improves glycemia control, insulin sensitivity, and dyslipidemia in $\mathrm{db} / \mathrm{db}$ mice. Diabetes. 57:2199-2210.

46. Klein, D.K., et al. 2007. Lack of AMPKalpha2 enhances pyruvate dehydrogenase activity during exercise. Am. J. Physiol. Endocrinol. Metab. 293:E1242-E1249.

47. Winder, W.W., and Hardie, D.G. 1996. Inactivation of acetyl-CoA carboxylase and activation of AMPactivated protein kinase in muscle during exercise. Am. J. Physiol. 270:E299-E304.

48. Faupel, R.P., Seitz, H.J., Tarnowski, W., Thiemann, V., and Weiss, C. 1972. The problem of tissue sampling from experimental animals with respect to freezing technique, anoxia, stress and narcosis. A new method for sampling rat liver tissue and the physiological values of glycolytic intermediates and related compounds. Arch. Biochem. Biophys. 148:509-522.

49. Jiang, G., and Zhang, B.B. 2003. Glucagon and regulation of glucose metabolism. Am. J. Physiol. Endocrinol. Metab. 284:E671-E678.

50. Richter, E.A., and Ruderman, N.B. 2009. AMPK and the biochemistry of exercise: implications for human health and disease. Biochem. J. 418:261-275.

51. Gauthier, M.S., et al. 2008. AMP-activated protein kinase is activated as a consequence of lipolysis in the adipocyte: potential mechanism and physiological relevance. J. Biol. Chem. 283:16514-16524.

52. Koh, H.J., et al. 2007. Adrenaline is a critical mediator of acute exercise-induced AMP-activated protein kinase activation in adipocytes. Biochem. J. 403:473-481.

53. Burgess, S.C., et al. 2004. Impaired tricarboxylic acid cycle activity in mouse livers lacking cytosolic phosphoenolpyruvate carboxykinase. J. Biol. Chem. 279:48941-48949.

54. Burgess, S.C., et al. 2007. Cytosolic phosphoenolpyruvate carboxykinase does not solely control the rate of hepatic gluconeogenesis in the intact mouse liver. Cell Metab. 5:313-320.

55. She, P., et al. 2000. Phosphoenolpyruvate carboxykinase is necessary for the integration of hepatic energy metabolism. Mol. Cell. Biol. 20:6508-6517.

56. Sakamoto, K., Goransson, O., Hardie, D.G., and Alessi, D.R. 2004. Activity of LKB1 and AMPKrelated kinases in skeletal muscle: effects of contraction, phenformin, and AICAR. Am. J. Physiol. Endocrinol. Metab. 287:E310-E317.

57. Woods, A., et al. 2003. LKB1 is the upstream kinase in the AMP-activated protein kinase cascade. Curr. Biol. 13:2004-2008.

58. Davies, S.P., Helps, N.R., Cohen, P.T., and Hardie, D.G. 1995. 5'-AMP inhibits dephosphorylation, as well as promoting phosphorylation, of the AMPactivated protein kinase. Studies using bacterially expressed human protein phosphatase-2C alpha and native bovine protein phosphatase-2AC. FEBS Lett. 377:421-425.

59. Sanders, M.J., Grondin, P.O., Hegarty, B.D. Snowden, M.A., and Carling, D. 2007. Investigating the mechanism for AMP activation of the AMP-activated protein kinase cascade. Biochem. J. 403:139-148.

60. Suter, M., et al. 2006. Dissecting the role of 5'-AMP for allosteric stimulation, activation, and deactivation of AMP-activated protein kinase. J. Biol. Chem. 281:32207-32216.

61. McGee, S.L., and Hargreaves, M. 2008. AMPK and transcriptional regulation. Front. Biosci. 13:3022-3033.

62. Feige, J.N., et al. 2008. Specific SIRT1 activation mimics low energy levels and protects against dietinduced metabolic disorders by enhancing fat oxidation. Cell Metab. 8:347-358.

63. Canto, C., et al. 2009. AMPK regulates energy expenditure by modulating $\mathrm{NAD}(+)$ metabolism and SIRT1 activity. Nature. 458:1056-1060.

64. McGuinness, O.P., Burgin, K., Moran, C., Bracy, D., and Cherrington, A.D. 1994. Role of glucagon in the metabolic response to stress hormone infusion in the conscious dog. Am. J. Physiol. 266:E438-E447.

65. Stevenson, R.W., et al. 1987. Similar dose responsiveness of hepatic glycogenolysis and gluconeogenesis to glucagon in vivo. Diabetes. 36:382-389.

66. Gurd, B.J., Yoshida, Y., Lally, J., Holloway, G.P., and Bonen, A. 2009. The deacetylase enzyme SIRT1 is not associated with oxidative capacity in rat heart and skeletal muscle and its overexpression reduces mitochondrial biogenesis. J. Physiol. 587:1817-1828.

67. Nair, S., Chacko, V.P., Arnold, C., and Diehl, A.M. 
2003. Hepatic ATP reserve and efficiency of replenishing: comparison between obese and nonobese normal individuals. Am. J. Gastroenterol. 98:466-470.

68. Solga, S.F., et al. 2008. Hepatic fat and adenosine triphosphate measurement in overweight and obese adults using $1 \mathrm{H}$ and $31 \mathrm{P}$ magnetic resonance spectroscopy. Liver Int. 28:675-681.

69. Lowell, B.B., and Shulman, G.I. 2005. Mitochondrial dysfunction and type 2 diabetes. Science. 307:384-387.

70. Mantena, S.K., et al. 2009. High fat diet induces dysregulation of hepatic oxygen gradients and mitochondrial function in vivo. Biochem. J. 417:183-193.
71. Garcia-Villafranca, J., Guillen, A., and Castro, J. 2008. Ethanol consumption impairs regulation of fatty acid metabolism by decreasing the activity of AMP-activated protein kinase in rat liver. Biochimie. 90:460-466.

72. Sriwijitkamol, A., et al. 2007. Effect of acute exercise on AMPK signaling in skeletal muscle of subjects with type 2 diabetes: a time-course and doseresponse study. Diabetes. 56:836-848.

73. Zhou, G., et al. 2001. Role of AMP-activated protein kinase in mechanism of metformin action. J. Clin. Invest. 108:1167-1174.

74. Ayala, J.E., Bracy, D.P., McGuinness, O.P., and Was- serman, D.H. 2006. Considerations in the design of hyperinsulinemic-euglycemic clamps in the conscious mouse. Diabetes. 55:390-397.

75. Chan, T.M., and Exton, J.H. 1976. A rapid method for the determination of glycogen content and radioactivity in small quantities of tissue or isolated hepatocytes. Anal. Biochem. 71:96-105.

76. Morgan, C.R., and Lazarow, A. 1962. Immunoassay of insulin using a two-antibody system. Proc. Soc. Exp. Biol. Med. 110:29-32.

77. Macdonald, I.A., and Lake, D.M. 1985. An improved technique for extracting catecholamines from body fluids. J. Neurosci. Methods. 13:239-248. 